\title{
La desigualdad y su resurgimiento en las agendas académicas
}

ATKINSON, ANTHONY B. (2015). Inequality: what can be done? Cambridge, MA: Harvard University Press. 384 pp.

La desigualdad es uno de los fenómenos transversales a los diferentes ámbitos de la sociedad. Hay quienes antes de considerarlo un problema, lo consideran una cuestión natural, o quienes lo consideran un estímulo para progresar, como frecuentemente se argumenta entre académicos y personajes de la política. Sin embargo, la desigualdad, entendida en su dimensión económica, se ha tornado un problema cada vez más relevante tanto en agendas académicas como políticas, de hecho, la Organización para la Cooperación y el Desarrollo Económicos (OECD por sus siglas en inglés), ha venido advirtiendo en diferentes reportes sobre el aumento en la desigualdad de ingresos desde hace dos décadas (OECD, 2008), tendencia que no solo se ha mantenido sino que se incrementó después de la última crisis financiera de 2008 y 2009, alcanzando máximos históricos en algunos países (OECD, 2015).

Más allá de los reportes, advertencias y columnas de prensa, no mucho se ha escrito al respecto, o por lo menos no mucho que pueda ser leído y discutido entre un amplio público sin formación en Economía. No obstante, un importante grupo de académicos de esta disciplina ha venido trabajando el tema y ha logrado alcanzar una significativa visibilidad; y gracias a la disponibilidad de datos estadísticos que cubren décadas enteras, han logrado evidenciar los alarmantes niveles que está alcanzado la desigualdad en varios países. Uno de los más recientes libros que aborda el tema fue escrito por el economista francés Thomas Piketty, quien en El Capital en el Siglo XXI presenta esta- 
dísticas desde inicios del siglo XX. Si bien este libro no es el reseñado aquí, es referencia importante dada la divulgación que alcanzó, no solo en los países en él analizados sino en otros que padecen altos niveles de desigualdad. El Capital en el Siglo XXI demuestra que cuando la tasa de retorno del capital es mayor a la tasa de crecimiento económico, hay un incremento significativo en la desigualdad de ingresos, pues en periodos con crecimiento económico estancado la importancia de la riqueza acumulada aumenta y se traduce en mayores ingresos para los dueños del capital (Piketty, 2014).

Ahora bien, ¿qué puede hacerse al respecto? Anthony B. Atkinson, reconocido economista británico, quien ha trabajado por más de 40 años en temas de pobreza y desigualdad, y quien ha sido mentor de Piketty, ofrece varias respuestas a esta pregunta en Inequality: what can be done? En un lenguaje claro y conciso, abarca ampliamente el tema de la desigualdad y abre la Economía, un terreno hostil para muchos, para que otras disciplinas entren a la discusión. En este sentido, Atkinson inicia reconociendo que los modelos económicos actuales omiten las cuestiones distributivas, sin embargo, advierte que es necesario discutir qué tan justos o no son los resultados de estos modelos.

El libro está dividido en tres partes. En la primera parte (Diagnóstico), Atkinson explica qué se entiende por desigualdad, cuál es su nivel actual, en qué periodos ha disminuido y qué lecciones se pueden extraer de esos periodos. Atkinson establece diferencias conceptuales, delimitando la desigualdad a su dimensión económica y proponiendo una lectura histórica del tema. En esta parte el autor diferencia entre preocupaciones intrínsecas e instrumentales por la desigualdad. En el caso de las preocupaciones intrínsecas, Atkinson retoma argumentos propios del utilitarismo y de la teoría de la justicia rawlsiana, pasando rápidamente a enfocarse en el segundo tipo de preocupaciones, las cuales agrupan los efectos sobre el desempeño económico y político de una sociedad. Posteriormente, Atkinson muestra a partir de datos cómo ha variado la desigualdad desde la segunda mitad del siglo XX hasta la actualidad, resaltando la diferencia entre los niveles de desigualdad de las décadas de la $2^{\mathrm{a}}$ posguerra hasta los 70, y los niveles que vienen evidenciándose desde los 80. El propósito de esta lectura será entender por qué hasta los 80 disminuyó la desigualdad y qué factores llevaron a su incremento a partir de esa década.

A lo largo de la primera parte del libro, Atkinson va dejando algunas frases en el camino, más que ideas sueltas parecen pistas o invitaciones a entrar en la discusión: cuando asevera que no hay una sola Economía, o cuando afirma que "el incremento en la desigualdad puede rastrearse en muchos casos, directa o indirectamente, en los cambios en la balanza de poder" (Atkinson, 2015: 82-3). Si bien no profundiza en ninguna de las dos afirmaciones, ambas parecieran sugerir un espacio para realizar aportes desde otras áreas.

En la segunda parte (Propuestas para la acción), Atkinson presenta 15 propuestas para reducir el alcance de la desigualdad. Aunque estas propuestas no son un 'paquete' 
o 'combo', tienen entre ellas un alto grado de interdependencia. Tienen como factor común la intervención del Estado, ya sea mediante impuestos o mediante la creación de autoridades soberanas que administren fondos públicos; y si bien sería difícil considerar radical alguna de sus propuestas, la implementación de algunas implicaría un significativo cambio de dirección en las medidas que actualmente se implementan en muchos países, como la privatización de los servicios de salud y la disminución del rol de los sindicatos.

En la tercera y última parte (Qué se puede hacer), Atkinson considera una serie de objeciones que pueden hacerse a sus 15 propuestas, probando entonces la factibilidad de cada una de ellas y considerando restricciones como la globalización y los déficit presupuestarios. Atkinson reconoce aquí los riesgos de los macro-acuerdos, como el Tratado Transatlántico de Comercio e Inversiones (TTIP por sus siglas en inglés), el cual restringiría la capacidad de acción de los gobiernos, sindicatos y personas en general contra las grandes corporaciones. Sin embargo, Atkinson asegura que el impacto de la globalización, dentro de la cual se enmarca dicho macro-acuerdo, sobre los niveles de desigualdad, depende en gran medida de las políticas domésticas.

Finalmente, Atkinson retoma la experiencia histórica para recordar que uno de los factores más importantes al momento de reducir la desigualdad ha sido la intervención exitosa del gobierno.

\section{Pertinencia para el caso latinoamericano y comentarios finales}

Tanto el libro de Atkinson como el de Piketty basan sus argumentos y propuestas en estadísticas de países miembros de la OECD, dentro de la cual solo hay dos latinoamericanos: Chile y México. En este sentido cabría preguntarse qué tan pertinente son estas propuestas para los países latinoamericanos: ¿la desigualdad en estos países ha seguido la misma tendencia?, ¿cuán mayor o menor es el nivel de desigualdad en América Latina con respecto a los países miembros de la OECD?

El tema de la desigualdad en América Latina es abordado marginalmente en los trabajos hasta aquí citados, y normalmente lo es para resaltar la tendencia contraria que se observó en ellos durante la primera década del siglo XXI, periodo en el que el nivel de desigualdad disminuyó para la mayoría de países latinoamericanos (Cornia, 2012; López-Calva y Lustig, 2010). Sin embargo, en un reciente informe de la Comisión Económica para América Latina y el Caribe (CEPAL), se muestra que, aunque la desigualdad ha disminuido en varios países de la región, en 2014 el ingreso del 10\% más rico de la población fue 14 veces mayor al del 40\% de la población con menores ingresos (CEPAL, 2015). Sumado a lo anterior, el informe advierte que, debido a la generalizada desaceleración económica desde el año 2010, el gasto social ha disminuido como 
consecuencia de la menor recaudación fiscal (CEPAL, 2015), situación que terminará impactando el nivel de desigualdad en la región.

El panorama evidentemente no es el más alentador en términos distributivos. La región, aunque ha mostrado una tendencia contraria a la global, sigue teniendo un alto nivel de desigualdad, y su ritmo de disminución se ha desacelerado. Es por esta razón que aportes como el de Atkinson deben tenerse presentes y deben ser incluidos tanto en los programas de estudio de las Ciencias Sociales como en las agendas de investigación, pues si bien en sus casos de estudio no hay países latinoamericanos, sus propuestas son lo suficientemente versátiles para aplicarse a diferentes países, además buscan abordar conocidos problemas de la región, tales como el desempleo, la disminución de transferencias sociales de carácter distributivo y las menores tasas de impuestos a los ingresos más altos, entre otros aspectos que requieren el regreso del Estado de Bienestar para el caso de los países desarrollados, y la construcción de uno para el caso de los emergentes.

\section{Referencias}

ATKINSON, A. (2015). Inequality: what can be done? Cambridge, MA: Harvard University Press.

CEPAL. (2015). Panorama Social de América Latina. Santiago de Chile: Naciones Unidas

CORNIA, GIOVANNI (2012). Inequality Trends and their Determinants. Latin America over 1990-2010.

UNU-WIDER. Working Paper No. 2012/o9

LÓPEZ-CALVA, LUIS F. y Lustig, N. (2010). “Explaining the Decline in Inequality in Latin America: Technological Change, Educational Upgrading, and Democracy”. En López-Calva, L. y Lustig, N. (eds), Declining Inequality in Latin America: A Decade of Progress?. New York, United Nations Developed Programme

OECD. (2008). Growing Unequal? Income Distribution and Poverty in OECD Countries. OECD publishing. OECD. (2015). In It Together: Why Less Inequality Benefits All. OECD publishing.

PIKETTY, T. (2014). Capital in The Twenty-first Century. London-Cambridge, The Belknap Press of Harvard University Press. 